\title{
MAINTENANCE THERAPY FOR ACUTE MYELOGENOUS LEUKAEMIA
}

\author{
AZIZ MA ${ }^{1}$, IRSHADULLAH NM ${ }^{2}$, ALI M $^{3}$, ISLAM $\mathrm{S}^{4}$, ISLAM MS ${ }^{5}$, BEGUM M$^{6}$, AFROZ R $^{7}$, HELAL AFM $^{8}$
}

\begin{abstract}
:
Acute myelogenous leukaemia (AML) is one of the deadliest malignancies of mankind. With optimum treatment long term survival is still less than half the patients treated. Except acute promyelocytic leukaemia (AML - M3), maintenance therapy in recent protocols are not recommended. This article discusses potential benefit of maintenance therapy for all AML patients, especially in facilities available in developing countries like Bangladesh.
\end{abstract}

Keywords: Acute myelogenous leukaemia (AML), maintenance therapy.

J Dhaka Med Coll. 2015; 24(1) : 67-72.

\section{Introduction:}

Treatment for acute myeloid leukaemia (AML) is one of the least satisfactory treatments for cancer. The best modality of treatment is still being searched for, and cure is not possible for more than half the patients. ${ }^{1}$

Regarding acute leukaemias, successful treatment started with childhood acute lymphoblastic leukaemia (ALL). ${ }^{2}$ Treatments for adult ALL are based on experience from childhood ALL protocols. ${ }^{3}$ Before identifying the different pathobiology of AML and ALL, the former was treated with ALL-like protocols ${ }^{4-8}$ but were less successful. Being a relatively less aggressive disease than AML, ALL treatment also appears to be less aggressive, except poor prognostic and CNS-directed regimens. It is based on vincristine and corticosteroids along with other 2-3 drugs, and stratified into induction of remission, consolidation with intermittent intensification and maintenance phases. AML treatment initially also used similar drugs and courses, but later on it was found that an anthracycline and ara-c, at higher doses than that in ALL, are enough to achieve remission with acceptable toxicity, ${ }^{9}$ and aggressive consolidation, by chemotherapy ${ }^{10,11}$ or stem cell transplantation (SCT), is all that needed for the best outcome. ${ }^{12}$ This understanding was not very clear cut in early era of AML treatment, that is why there was a trend for maintenance therapy, and still there are arguments for that. Among the acute leukaemias, ALL and acute promyelocytic leukaemia (APL, or, $\mathrm{AML}-\mathrm{M}_{3}$ ) requires maintenance therapies for 2-3 years. Evidences and justifications for maintenance therapy in other AMLs is discussed in this article.

\section{Overview of AML treatment:}

The aim of induction of remission therapy in acute leukaemias is to make the patient symptom free and the bone marrow blast free (though $<5 \%$ blast is acceptable to avoid over

1. Dr. Md. Abdul Aziz, Associate Professor, Department of Haematology, BSMMU, Dhaka, Bangladesh

2. Dr. Naseeb M Irshadullah, Resident, Phase-B (Haematology), Department of Haematology, BSMMU, Dhaka, Bangladesh

3. Dr. Mohammad Ali, Resident Physician, Department of Haematology, DMCH, Dhaka, Bangladesh

4. Dr. Shafiqul Islam, Medical Officer, Department of Haematology, BSMMU, Dhaka, Bangladesh

5. Dr. Sirajul Islam, Associate Professor, Department of Haematology, Mymensingh Medical College, Bangladesh.

6. Prof. Dr. Masuda Begum, Chairman, Department of Haematology, BSMMU, Dhaka, Bangladesh

7. Dr. Rafia Afrose, Medical Officer, Department of Haematology, Dhaka Medical College Hospital, Dhaka

8. Dr. Abul Fazal Mohammad Helal, Assistant Professor, Department of Medicine, Sir Salimullah Medical College, Mitford, Dhaka.

Correspondence: Dr. Md. Abdul Aziz, Associate Professor, Department of Haematology, BSMMU, Dhaka, Bangladesh, Email: azizfcps@yahoo.com, Mobile no: 01712463976 
treatment at induction). Consolidation therapy reduces blast cells further and thus preventing early relapse, and, maintenance therapy for months or even for years prevents late relapse of the disease from 'sanctuary' sites. In early era of AML treatment, ALL-like protocols were used, but with lesser success. In 1982, Estey et al., tried to evaluate cause of initial induction failure in AML. They studied drugs used between 1973 and 1979, i.e., combination of anthracycline, cytosine arabinoside, vincristine, and prednisone, for up to 4 courses, but complete remission rate was $56 \% .{ }^{13}$ It became evident that biology of these 2 cancers are different. Two to 5 drugs were used in induction (reviewed by Irshadullah) ${ }^{14}$ but an anthracycline and ara-c became gold standard for induction, ${ }^{11,15-17}$ and consolidation therapy consisted of similar drugs as in induction or additional drugs or high dose ara-c. ${ }^{18}$ With the spread of SCT numerous studies were done to compare chemotherapy vs. SCT as consolidation therapy, and for poor cytogenetic patients now SCT is the first choice if condition of the patient allows and suitable donor is available. ${ }^{13,18}$ If the disease relapses or become refractory after many chemotherapy courses, palliative chemotherapy is still an option which continues as long as the patient's condition and desire, and physician's judgment allow. ${ }^{13}$ Present treatment plan in developed country is so aggressive that maintenance therapy fails to show any benefit in cure rate. ${ }^{19,20}$ Probably that is the main reason why routine maintenance therapy is omitted from the latest algorithms of AML treatment.

\section{Evidence for maintenance chemotherapy in AML:}

As already mentioned, a lot of early studies with AML consisted of maintenance chemotherapy for years, and it appeared to be a routine practice like in ALL. Earliest studies tried immunotherapy with vaccination for $\mathrm{BCG},{ }^{21}$ viral oncolysate (i.e., avian influenza virusinfected, formalin-inactivated, allogeneic leukaemia cells), ${ }^{22}$ ex vivo treated blast cells and sensitized lymphocytes. ${ }^{23}$ Later on interferon (IFN) was tried after its success in chronic myeloid leukaemia (CML). ${ }^{24}$ Among the cytotoxic drugs ${ }^{25-45}$ monthly doses of various combinations of low dose ara-c (LDA), thioguanine and 6-mercaptopurine were tried. Maintenance therapies were strengthened ('intensified') by intermittent myelosuppressive chemotherapies like DA or other induction regimens at standard or reduced dose. Most of the studies were done in the last century, but there are some relatively recent studies and reviews favouring or indicating possible benefit of maintenance therapy with both newer \& older drugs. Randomized trials showed that maintenance therapy may prolong initial remissions. ${ }^{46,47}$ It was found that short term maintenance was not effective in improving disease free survival (DFS) or overall survival (OS). ${ }^{48}$ For example, by Kantarjian et al. maintenance therapy used was three cycles of Ara-C thioguanine (AT), followed by three cycles of cyclophosphamide and rubidazone with vincristine and prednisone (CROP), median total duration of therapy was only 9 months. Many study outcomes and reviews stated against beneficial effects of maintenance therapy, rather they appear as one form of palliative measure. ${ }^{49-54}$ On the other hand, it was argued that some of the studies not showing efficacy of maintenance therapies used inadequate drugs and/or inadequate doses. ${ }^{41}$

\section{The Bangladesh perspective:}

The picture of our country is quite different from the places where the above mentioned studies were done. Here, no randomized controlled study was done to reveal efficacy or failure of maintenance therapy for AML, even though our experience might go in favour for maintenance therapy. If we start from the very beginning of management of an AML patient, we see that routine cytogenetic evaluation still not done here at diagnosis, and so we lose, not only the benefit of developing treatment plan for individual patient, but also assessing minimal residual disease (MRD) status after achieving remission. Moreover, when induction therapy is given, it is almost always a compromised dose or duration, or both, to prevent the patient from induction death due to inadequate blood product support or from infections, especially the fungal ones, which are almost never diagnosed. Though the ideal 
recommendation is to start the consolidation therapy just after recovery of marrow from induction chemotherapy, financial and physical 'recovery' is usually awaited and many a time consolidation is delayed for weeks, if not for months. Further harm to optimum treatment are observed because there are gaps in between the consolidation cycles and there are examples where patients could not afford all 3-4 cycles of consolidation, or experienced relapse before completing all consolidation cycles. So, among the few patients who remain under follow up, relapse within a year or two is the rule, though most of the patients are missed from follow up, especially when they learn about the prognosis.

In developed countries acute leukaemias are treated with an intention to cure. That is why they recommend allogeneic SCT as a routine for poor prognostic diseases. The treatment related mortality (TRM) for allogeneic SCT is between $20-40 \%$, there are also some failures and early relapses, and so outcome of this most aggressive modality of treatment may offer chance to cure but in expense of much cost and therapeutic complications. SCT status in Bangladesh is far from a way to cure for acute leukaemias. Even if it is established, the cost of allogeneic SCT would be far away from the reach of the majority AML patients of this country and who would afford to undergo the procedure would also be able to go to other countries which have much experience in this field. That is why, for now and for the next several years, it is expected that, we will stay exclusively with chemotherapies for the treatment of acute leukaemias. If we realize this, and also realize the fact that, in the present infrastructure and supportive care facility, chemotherapy regimens invented and recommended by developed countries cannot be followed in toto, we should not aim cure, but survival and quality of life of the patients. In this respect, induction of remission, compromised consolidation and a handsome regimen as maintenance can increase longevity with acceptable complications and cost.

\section{Conclusion:}

Studies with long term follow up of leukaemia patients are rarely designed in our country. Now that communication facilities developed much, reports can be collected and patients can be visually communicated over the internet, long term substantial follow ups are possible now. Many haematologists working throughout the country can be the sources of a large amount of data. We should formulate multi-centre welldesigned comparative studies to substantiate the effect of maintenance therapy in our settings. We hope all the haematologists of this country will step forward to this goal.

\section{References:}

1. Lichtman MA, Liesveld JL. Acute Myelogenous Leukemia. In: Kaushansky K, Beutler E, Seligsohn U, Lichtman MA, Kipps TJ, Prchal JT, eds. Williams Hematology. $8^{\text {th }}$ ed. New York: McGrawHill; 2010.

2. American Cancer Society. The History of Cancer [Internet]. 2014 [cited 2015, March 22] Available from: http://www.cancer.org/acs/groups/ cid/ documents/webcontent/002048-pdf. df.

3. Coutre SE. Acute Lymphoblastic Leukemia in Adults. In: Greer JP, Arber DA, Glader B, List AF, Means RT Jr., Paraskevas F, et al. eds. Wintrobe's Clinical Hematology. $13^{\text {th }}$ ed. Philadelphia: Lippincott Williams \& Wilkins; 2013.

4. Kawamura S, Kawarada R, Tsushima Y, Sawada Y, Yoshida Y, Chiba Y, et al. An intensification therapy of adults acute leukaemia. Gan To Kagaku Ryoho. 1989; 16(1): 83-7.

5. Seo T, Fukushima T, Inoue H, Imamura S, Urasaki Y, Yoshida A, et al. Long-term follow-up of the clinical efficacy of chemotherapy for acute myeloid leukemia at a single institute. J Infect Chemother. 2001 Sep;7(3):156-62.

6. Ohno R, Kobayashi T, Morishima Y, Hiraoka A, Imai $\mathrm{K}$, Asoh $\mathrm{N}$, Tsubaki $\mathrm{K}$, Tomonaga $\mathrm{M}$, Takahashi I, Kodera K, et al. Randomized study of individualized induction therapy with or without VCR, and of maintenance of 4 or 12 courses in adult AML: JALSG-AML87. Japan Adult Leukemia Study Group (JALSG). Leukaemia. 1992; 6 Suppl 2: 92-5.

7. Ohno R, Kobayashi T, Tanimoto M, Hiraoka A, Imai $\mathrm{K}$, Asou $\mathrm{N}$, et al. Randomized study of individualized induction therapy with or without vincristine, and of maintenance-intensification therapy between 4 or 12 courses in adult acute myeloid leukemia. AML-87 Study of the Japan 
Adult Leukemia Study Group. Cancer. 1993; 71(12): 3888-95.

8. Beguin Y, Bury J, Fillet G, Lennes G. Treatment of Acute Nonlymphocytic Leukaemia in Young and Elderly Patients. Cancer. 1985; 56(11): 2587-92.

9. Rowe JM. Optimal induction and post-remission therapy for AML in first remission. Hematology ASH Education Program. 2009: 396-405.

10. Robak T, Wierzbowska A. Current and emerging therapies for acute myeloid leukemia. Clin Ther. 2009; 31 Pt 2: 2349-70.

11. Peters WG, Willemze R., Colly LP. Preliminary results of consolidation therapy with high-dose cytosine arabinoside for patients with bad-risk or relapsed acute leukemia or lymphoblastic nonHodgkin's lymphoma. Eur J Cancer Clin Oncol. 1987; 23(4): 401-5.

12. National Comprehensive Cancer Network. Acute Myeloid Leukaemia. Version 1.2015. 2014 [cited 2015, March 27]. Available from http:// www.nccn.org/ professionals/physician_gls/ pdf/ aml.pdf.

13. Estey EH, Keating MJ, McCredie KB, Bodey GP, Freireich EJ. Causes of initial remission induction failure in acute myelogenous leukemia. Blood. 1982; 60(2): 309-15.

14. Irshadullah NM. Comparative Study Between Modified UK MRC AML 12 and Modified DA Protocols in BSMMU [MD thesis]. Dhaka: Bangabandhu Sheikh Mujib Medical University (BSMMU); 2015.

15. Gisselbrecht C, Lepage E, Lenoble M, Marty M, Boiron M. Therapy of acute leukemia in the adult. Role of anthracyclins. Pathol Biol (Paris). 1987; 35(1): 69-74.

16. Gmür J. Current status of therapy and prognosis in acute adult leukemia. Ther Umsch. 1996; 53(2): 111-6.

17. Rowe JM. What is the best induction regimen for acute myelogenous leukemia? Leukemia. 1998; 12 Suppl 1: S16-9.

18. Emadi A, Baer MR. Acute Myeloid Leukemia in Adults. In: Greer JP, Arber DA, Glader B, List AF, Means RT Jr., Paraskevas F, et al. eds. Wintrobe's Clinical Hematology. $13^{\text {th }}$ ed. Philadelphia: Lippincott Williams \& Wilkins; 2013.

19. Volger WR, Weiner RS, Moore JO, Omura GA, Bartolucci AA, Stagg M. Long-term follow-up of a randomized postinduction therapy trial in acute myelogenous leukemia (a Southeastern Cancer Study Group trial). Leukemia 1995; 9(9): 1456-60.
20. Sauter C, Berchtold W, Fopp M, et al. Acute myelogenous leukaemia: maintenance chemotherapy after early consolidation treatment does not prolong survival. Lancet 1984; 1(8373): 379-82.

21. Powles RL, Crowther D, Bateman CJ, Beard ME, McElwain TJ, Russell J, et al. Immunotherapy for acute myelogenous leukaemia. Br J Cancer. 1973; 28(5): 365-76.

22. Schuepbach J, Arrenbrecht S, Sauter C. Early antiviral antibody response after immunization with viral oncolysate: a powerful prognostic marker for acute myelogenous leukemia remission patients. Blood. 1983; 62(3): 616-21.

23. Reizenstein $\mathrm{P}$, Ogier C, Sjögren AM. Immunotherapy versus chemotherapy of acute myeloid leukemia: response to PHA, allogeneic lymphocytes, and leukemic myeloblasts of remission lymphocytes from leukemia patients. Recent Results Cancer Res. 1980; 75: 29-36.

24. McSweeney EN, Worman CP, Tsakona CP, Jewel AP, Hoffbrand AV, Milligan DW, et al. Low-dose recombinant alfa-2a-interferon: a feasible maintenance therapy in acute myeloid leukaemia in the older patient. Acta Haematol. 1993; 89(1): $1-5$.

25. Rai KR, Holland JF, Glidewell OJ, Weinberg V, Brunner K, Obrecht JP, et al. Treatment of acute myelocytic leukemia: a study by Cancer and Leukemia Group B. Blood. 1981; 58:1203-1212.

26. Creutzig U, Ritter J, Langermann HJ, Riehm H, Henze G, Niethammer D, et al. Acute myelogenous leukemia in children: results of the cooperative BFM-78 therapy study after $33 / 4$ years. Klin Padiatr. 1983; 195(3): 152-60.

27. Büchner T, Urbanitz D, Hiddemann W, Rühl H, Ludwig WD, Fischer $\mathrm{J}$, et al. Intensified induction and consolidation with or without maintenance chemotherapy for acute myeloid leukemia (AML): two multicenter studies of the German AML Cooperative Group. J Clin Oncol. 1985; 3(12): 1583-9.

28. Creutzig U, Ritter J, Riehm H, Langermann HJ, Henze G, Kabisch $\mathrm{H}$, et al. Improved treatment results in childhood acute myelogenous leukemia: a report of the German cooperative study AMLBFM-78. Blood. 1985; 65(2): 298-304.

29. Schellong G, Creutzig U, Ritter J. Treatment of acute myelogenous leukemia in children. Med Oncol Tumor Pharmacother. 1985; 2(1): 17-25.

30. Embury SH, Elias L, Heller PH, Hood CE, Greenberg PL, Schrier SL. Remission maintenance therapy in acute myelogenous leukemia. West $\mathrm{J}$ Med. 1977; 126(4): 267-72. 
31. Hewlett J, Kopecky KJ, Head D, Eyre HJ, Elias L, Kingsbury L, et al. A prospective evaluation of the roles of allogeneic marrow transplantation and low-dose monthly maintenance chemotherapy in the treatment of adult acute myelogenous leukemia (AML): a Southwest Oncology Group study. Leukemia. 1995; 9(4): 562-9.

32. Ohno R, Kobayashi T, Tanimoto M, Hiraoka A, Imai $\mathrm{K}$, Asou $\mathrm{N}$, et al. Randomized study of individualized induction therapy with or without vincristine, and of maintenance-intensification therapy between 4 or 12 courses in adult acute myeloid leukemia. AML-87 Study of the Japan Adult Leukemia Study Group. Cancer. 1993; 71(12): 3888-95.

33. Raza A, Preisler HD, Browman GP, Larson RA, Rustum YM, Goldberg J, et al. Long-term outcome of patients with acute myelogenous leukemia: the role of maintenance therapy, consolidation therapy and the predictive value of two in vitro assays. Leuk Lymphoma. 1993; 10(1-2): 57-66.

34. Büchner T, Hiddemann W, Schaefer UW, Löffler H, Maschmeyer G, Ludwig WD, et al. Combined effect of very early intensification and prolonged post-remission chemotherapy in patients with AML. Leukemia. 1992; 6 Suppl 4: 68-70.

35. Curtis JE, Messner HA, Minden MD, Lipton JH, Lockwood GA, Tritchler DL, et al. High-dose cytosine arabinoside remission induction for acute myelogenous leukemia: comparison of two regimens of remission maintenance. Leukemia. 1992; 6(11): 1192-8.

36. Ohno R, Kobayashi T, Morishima Y, Hiraoka A, Imai $\mathrm{K}$, Asoh $\mathrm{N}$, et al. Randomized study of individualized induction therapy with or without VCR, and of maintenance of 4 or 12 courses in adult AML: JALSG-AML87. Japan Adult Leukemia Study Group (JALSG). Leukemia. 1992; 6 Suppl 2: $92-5$.

37. Jehn U, Knüppel W, Wilmanns W. Intensive maintenance treatment in acute myelogenous leukemia (AML): single institution experience of a multicenter randomized trial. Onkologie. 1988; 11(1): 13-7.

38. Büchner T, Urbanitz D, Hiddemann W, Koch P, Pielken HJ, Kuse R, et al. Alternatives and further development of therapy of acute myeloid leukemia in adults. Update of West German multicenter studies. Onkologie. 1987; 10(1): 14-6.

39. Baer MR. Is there a role for maintenance therapy in acute myeloid leukaemia? Best Pract Res Clin Haematol. 2009; 22(4): 517-21.

40. Büchner T, Hiddemann W, Berdel WE, Wörmann B, Schoch C, Fonatsch C, et al. 6-Thioguanine, cytarabine, and daunorubicin (TAD) and high-dose cytarabine and mitoxantrone (HAM) for induction, TAD for consolidation, and either prolonged maintenance by reduced monthly TAD or TADHAM-TAD and one course of intensive consolidation by sequential HAM in adult patients at all ages with de novo acute myeloid leukemia $(\mathrm{AML})$ : a randomized trial of the German AML Cooperative Group. J Clin Oncol. 2003; 21(24): 4496-504.

41. Büchner T, Krug U, Berdel WE, Heinecke A, Sauerland MC, Wörmann B, et al. Maintenance for acute myeloid leukemia revisited. Curr Treat Options Oncol. 2007; 8(4): 296-304.

42. Wei A, Tan P, Perruzza S, Govindaraj C, Fleming $\mathrm{S}$, McManus $\mathrm{J}$, et al. Maintenance lenalidomide in combination with 5-azacitidine as postremission therapy for acute myeloid leukaemia. Br J Haematol. 2015; 169(2): 199-210.

43. Antar A, Kharfan-Dabaja MA, Mahfouz R, Bazarbachi A. Sorafenib Maintenance Appears Safe and Improves Clinical Outcomes in FLT3-ITD Acute Myeloid Leukemia After Allogeneic Hematopoietic Cell Transplantation. Clin Lymphoma Myeloma Leuk. 2015; 15(5): 298-302.

44. Ferrero D, Crisà E, Marmont F, Audisio E, Frairia C, Giai V, et al. Survival improvement of poorprognosis AML/MDS patients by maintenance treatment with low-dose chemotherapy and differentiating agents. Ann Hematol. 2014; 93(8): 1391-400.

45. Archimbaud E, Anglaret B, Thomas X, Jaubert J, Sebban C, Guyotat D, et al. Maintenance with lowdose cytarabine for acute myeloid leukemia in complete remission. Ann Hematol. 1992; 65(2): 71-4.

46. Cassileth PA, Harrington DP, Hines JD, et al. Maintenance chemotherapy prolongs remission duration in adult acute nonlymphocytic leukemia. J Clin Oncol 1988; 6(4): 583-7.

47. Dutcher JP, Wiernik PH, Markus S, Weinberg V, Schiffer CA, Harwood KV. Intensive maintenance therapy improves survival in adult acute nonlymphocytic leukemia: an eight-year followup. Leukemia. 1988; 2(7): 413-9.

48. Kantarjian HM, Keating MJ, Walters RS, McCredie KB, Bodey GP, Freireich EJ. Early intensification and short-term maintenance chemotherapy does not prolong survival in acute myelogenous leukemia. Cancer. 1986; 58(8): 1603-8.

49. Gale RP. Progress in acute myelogenous leukemia. Cancer Treat Rep. 1981; 65 Suppl 4: 87-92.

50. Wells RJ, Woods WG, Buckley JD, Odom LF, Benjamin D, Bernstein I, et al. Treatment of newly diagnosed children and adolescents with acute myeloid leukemia: a Childrens Cancer Group study. J Clin Oncol. 1994; 12(11): 2367-77. 
51. Wells RJ, Woods WG, Lampkin BC, Nesbit ME, Lee JW, Buckley JD, et al. Impact of high-dose cytarabine and asparaginase intensification on childhood acute myeloid leukemia: a report from the Childrens Cancer Group. J Clin Oncol. 1993; 11(3): 538-45.

52. Miyawaki S, Sakamaki H, Ohtake S, Emi N, Yagasaki F, Mitani $\mathrm{K}$, et al. A randomized, postremission comparison of four courses of standard-dose consolidation therapy without maintenance therapy versus three courses of standard-dose consolidation with maintenance therapy in adults with acute myeloid leukemia: the Japan Adult Leukemia Study Group AML 97 Study. Cancer. 2005; 104(12): 2726-34.

53. Wells RJ, Woods WG, Buckley JD, Odom LF, Benjamin D, Bernstein I, et al. Treatment of newly diagnosed children and adolescents with acute myeloid leukemia: a Children's Cancer Group study. J Clin Oncol. 1994; 12(11): 2367-77.

54. Rees JK, Gray RG, Wheatley K. Dose intensification in acute myeloid leukaemia: greater effectiveness at lower cost. Principal report of the Medical Research Council's AML9 study. MRC Leukaemia in Adults Working Party. $\mathrm{Br} \mathrm{J}$ Haematol. 1996; 94(1): 89-98. 